\title{
Caenorhabditis elegans: An Emerging Model System for Pesticide Neurotoxicity
}

\author{
KA McVey, JA Mink, IB Snapp, WS Timberlake, CE Todt, R Negga and VA Fitsanakis*
}

King College, Department of Biology, 1350 King College Road, Bristol, TN 37620, USA

\section{Caenorhabditis elegans as a Model System}

An ideal model organism should generally have three essential characteristics: successful sexual crosses should be easy to perform; a fully sequenced genome should be available; and it should be easy to induce reliable and reproducible DNA mutations [1]. The nematode Caenorhabditis elegans ( $C$. elegans), introduced to the broad scientific community by Brenner in 1974, fulfills each of these three essential guidelines [2]. Although initially used extensively by the developmental biology community, its recent adoption by the biomedical and environmental toxicology scientists has strengthened experimental design power in these fields [3]. Relative to traditional model organisms, e.g. rat, mouse, dog (mammals) and Arabidopsis (plants), the invertebrate species C. elegans has begun to be recognized as invaluable. For example, it requires a relatively small budget project compared to other possible organisms, is quite small and transparent, has a short lifespan and has relatively simple anatomy and physiology [4].

These characteristics provide for straightforward genetic manipulation, growth and observation within a laboratory environment for a wide array of experiments [5]. In particular, the small size of $C$. elegans allows for easy storage in small, dedicated laboratory areas, its transparency facilitates visualization under a microscope and the short life span enables assessment of multiple generations within days, making genetic studies related to inheritable disorders possible in a relatively short time frame. Furthermore, studies involving multiple generations are aided by the fact that $C$. elegans also exist as a selffertilizing hermaphrodite, preventing inbreeding [5]. C. elegans have also become more widely-used in toxicology due to their autonomic and somatic neural and molecular network similarities to humans $[6,7]$, allowing for valuable insight related to multiple vertebrate systems. Furthermore, as a fully intact in vivo model organism, scientists can study multiple complex behaviors, such as searching for food and/or mates [8-11]. Interestingly, C. elegans is rarely found in the wild, although does lives in tropical and subtropical areas and is more typically found cultured in laboratories [12]. Some major areas where C. elegans is becoming increasing used include mechanistic toxicology, environmental toxicology and high-throughput screening [3]. A major methodological breakthrough came when it was recognized that $C$. elegans could easily be manipulated through RNA interference, or RNAi [13-15]. This technique involves the introduction of exogenous RNA to complement endogenous RNA, which then "interferes" with the translation of the target gene. The silencing of this expression potentially helps the scientific community better understand the function of the gene's product [16-18]. Extensive experimentation with C. elegans has produced complete neuronal and developmental wiring diagrams that have been confirmed by numerous labs $[3,19]$. Furthermore, these networks are known to be similar in humans, providing additional justification for comparing two widely diverse organisms [5]. On the other hand, the developmental pattern of C. elegans is vastly different from most animals in that they display a "mosaic structure" in which the entire developmental process will not proceed correctly if any cell is removed. This is in contrast to other model organisms, such as the fruit fly, where the removal of a single cell, or even multiple cells, may have no effect on the developmental fate of the organism [5]. C. elegans has been used to further the study of neurodegenerative and transgenic diseases in humans [4], including Huntington's, Alzheimer's and Parkinson's diseases [20-25]. In fact, C. elegans genes related to these three diseases are substantially comparable with human genes [1]. For example, about $40-75 \%$ of human genes identified as disease-related are analogous to those found in C. elegans $[1,26]$. Other similarities exist between C. elegans stem cells and those of "higher" organisms, including humans $[27,28]$. Thus, comparisons between worms and humans have already provided important insights into possible causes and potential treatments for many diseases. Furthermore, since $C$. elegans are easy to genetically manipulate, this facilitates research involving the interplay of the genetic and environmental aspects of many neurodegenerative diseases [3]. As such, C. elegans can be easily treated with or introduced to specific chemicals thought to contribute to neurodegeneration through interactions with various genetic mutations [4]. More recently, C. elegans has proven to be a beneficial model organism for studies of major pesticides classes, including organophosphates (OPs) and dithiocarbamates (DTCs). Using C. elegans, scientists can study the various effects these agrochemicals may exert on humans [3,29-31]. For example, in a study involving OPs and C. elegans, alterations in gene and protein expression were examined [32], particularly nervous system-specific endpoints.

\section{The Nervous System of C. elegans}

\section{Overview}

Starting in the mid 1990s C. elegans became a more widely-used model in the neurotoxicology community $[3,29,31,33]$. This was partly due to the simplicity of their nervous system, which is a relatively small neuronal network that is highly stereotypical from animal to animal [6]. A total of 302 neurons and 56 glial cells (e.g., CEP sheath glia) make up the hermaphrodite's nervous system, whereas the males have 381 neurons and 92 glial cells $[34,35]$. As in more complex model organisms, their neurons are involved in multiple synaptic contacts, including chemical synapses, gap junctions [36] and neuromuscular junctions [6]. About half of the neuronal cell bodies are found in the head, surrounding the dorsal nerve ring, while the remaining soma are found along the ventral cord and in tail ganglia [34]. Furthermore,

*Corresponding author: VA Fitsanakis, King College, Department of Biology,1350 King College Road, Bristol, TN 37620, USA, Tel: 423-652-6322; Fax: 423-652-4833; E-mail: vafitsan@king.edu

Received December 07, 2011; Accepted February 14, 2012; Published February 16, 2012

Citation: McVey KA, Mink JA, Snapp IB, Timberlake WS, Todt CE, et al. (2012) Caenorhabditis elegans: An Emerging Model System for Pesticide Neurotoxicity. Environment Analytic Toxicol S4:003. doi:10.4172/2161-0525.S4-003

Copyright: (C) 2012 McVey KA, et al. This is an open-access article distributed under the terms of the Creative Commons Attribution License, which permits unrestricted use, distribution, and reproduction in any medium, provided the original author and source are credited. 
the nervous system of C. elegans is divided into a pharyngeal nervous system, containing 20 neurons and the somatic nervous system, which contains 282 neurons (Figure 1). All together, an extensive neuronal network wiring diagram has been constructed consisting of 6393 chemical synapses, 890 gap junctions and 1410 neuromuscular junctions [6,37]. Interestingly, a single neuron can make synaptic contact with anywhere from one to thirty other neurons; on average, however, they synapse with around fifteen of the neurons with which they make physical contact $[6,34,37,38]$. Based on structural and functional properties, the neurons are divided into three categories: sensory neurons, interneurons and motor neurons. Motor neurons are easily defined by the presence of a neuromuscular junction and interneurons constitute about half of all the neurons present [6].

\section{Sensory neurons}

As in higher organisms, sensory neurons are classified by their ability to respond to specific environmental stimuli and these neurons account for about one-third of those in the nematode [39-41]. Most sensory neurons are found in the head [42] and the majority are dedicated to thermosensation $[42,43]$. Temperature detection and regulation is quite important for many aspects of these worms [41,4447]. For example, C. elegans can only grow and reproduce between $12^{\circ}$ $27^{\circ} \mathrm{C}[34,44]$. Within this temperature range, well-fed nematodes track isotherms, a major component of food-searching strategy that requires constant reorientation of the head $[34,46]$. The main thermosensors are a pair of neurons, called amphid finger neurons (AFD), that are located in the head and help mediate behavior [48].

C. elegans also respond to many types of mechanical stimuli, including nose touch, mating cues and the viscosity of the bacterial food lawn [48]. These mechanical neurons function through the use of two neurotransmitters: $\gamma$-aminobutyric acid (GABA) and acetylcholine $[42,49]$. When the nose is touched, the sensation detected by ciliated neurons cause the worm to reverse direction $[48,50,51]$. This response is mediated by three sets of ciliated head neurons: two amphid sensilla (ASH) neurons, four outer labial sensilla (OLQ) neurons and two inner labial sensilla (FLP) neurons [49,52,53]. Each type mediates only a fraction of the behavior, for example: ASH $45 \%$, FLP 29\% and OLQ 5\% [48]. As with many other organisms, the mating behavior of C. elegans is the one most complex, but it is largely one- sided: males can be described as "obsessed" with pursuing the selffertile hermaphrodites [54,55]. The male mating ritual is typically divided into six steps: 1) attraction to hermaphrodite chemical cues; 2) response to contact with the hermaphrodite; 3 ) backing and turning along the mates body; 4) vulva location; 5) copulatory spicule insertion into the vulva; 6 ) and sperm transfer to the uterus $[48,55]$. Cilia are also required in this process to detect chemical and mechanical signals from the hermaphrodite [56].

\section{Neurotransmitters: Octopamine}

As mentioned previously, each C. elegans has 6393 chemical synapses that rely on numerous neurotransmitters [57-60]. Four biogenic amines, octopamine, tyramine, dopamine and serotonin (Table 1), are present in C. elegans [61]. In general, they are responsible for modulating behavioral responses to environmental changes [62]. For example, biogenic amines modulate egg laying, pharyngeal pumping, locomotion and learning [63-67]. Octopamine, which is not found in mammalian systems, is synthesized from tyramine by the enzyme tyramine $\beta$-hydroxylase, TBH-1 [61]. When C. elegans are exposed to exogenous octopamine, several behavioral effects, including inhibition of egg laying and pharyngeal pumping, are observed $[65,68]$.

\section{Neurotransmitters: Tyramine}

Tyramine is only synthesized in a few cells in C. elegans and is therefore found in small quantities [69,70]. It is required for the following functions: inhibition of head oscillations in response to being touched on the anterior portion of the body; inhibition of egg laying; and modulation of spontaneous reversals [61]. When a nematode is in starvation circumstances, tyramine is released to inhibit unnecessary functions so the worm can better focus on searching for food [71]. A newly identified tyramine receptor, SER-2, binds the neurotransmitter with high affinity and when mutations are present, behavioral defects are seen [66]. For example, SER-2 mutants fail to inhibit oscillations in response to touch [61]. Exogenous tyramine also blocks pharyngeal pumping, which is stimulated by serotonin, further supporting the idea that tyramine is released in response to food deprivation [72]. Tyramine also inhibits egg laying, but this most likely does not act through SER2. Rather, it is more likely that tyramine serves as an intermediate for octopaime which inhibits egg laying [61].

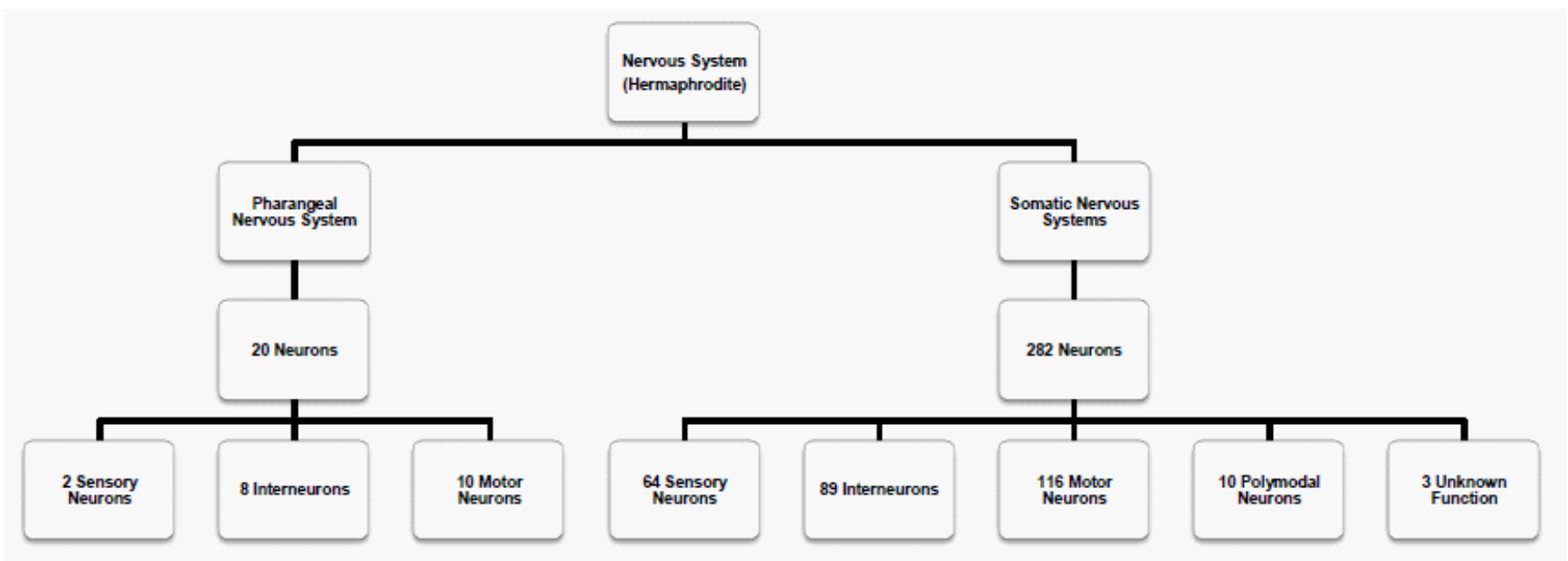

Figure 1: Nervous System of C. elegans. Summary of functional classification of neurons in C. elegans hermaphrodite. Based on [151]. 


\begin{tabular}{|l|l|l|l|l|l|}
\hline \multicolumn{2}{|c|}{ Major Functions of C. elegans Neurotransmitters } \\
\hline Octopamine & Egg laying & $\begin{array}{l}\text { Inhibition } \\
\text { Pharyngeal } \\
\text { pumping }\end{array}$ & & \\
\hline Tyramine & Egg laying & $\begin{array}{l}\text { Pharyngeal } \\
\text { pumping }\end{array}$ & $\begin{array}{l}\text { Spontaneous } \\
\text { reversal }\end{array}$ & & \\
\hline Dopamine & $\begin{array}{l}\text { Food-dependent forward } \\
\text { movement }\end{array}$ & & $\begin{array}{l}\text { Slows movements in the presence } \\
\text { of food }\end{array}$ & $\begin{array}{l}\text { High-angle } \\
\text { turning }\end{array}$ \\
\hline Serotonin & Locomotion & Defecation & $\begin{array}{l}\text { Learning } \\
\text { behaviors }\end{array}$ \\
\hline GABA & Muscle contraction & & & Muscle relaxation \\
\hline Acetylcholine & & & Muscle contractions \\
\hline
\end{tabular}

Table 1: Summary of major functions associated with neurotransmitters in C. elegans.

\section{Neurotransmitters: Dopamine}

The neurotransmitter dopamine is found in eight neurons in the C. elegans hermaphrodite and in fourteen additional neurons located in the tail of the male $[61,73]$. The role of dopaminergic neurons in C. elegans is thought to be predominantly mechanosensory in nature [42]. Supporting evidence indicates a lack in the animal's ability to respond to environmental changes when dopamine is inhibited $[74,75]$. Dopamine signaling in C. elegans also has established roles in regulating locomotion and learning [61]. For example, dopamine signaling facilitates the response of C. elegans to environmental changes by modulating locomotion. Well-fed wild-type nematodes slow their movements when they encounter a food source, a process requiring dopamine release [76,77]. Nematodes that have their dopaminergic neurons ablated fail to exhibit this "slowing" process, further supporting the supposition that these neurons are mechanosensory and that slowing is likely caused by physical stimuli [78]. Dopamine signaling also leads to more efficient searches for new food sources. After wild-type nematodes exhaust an immediate food supply, they continue to search the nearby area before expanding their exploration [79]. This localized search is referred to as "restricted searching" and is characterized by high-angled turns [61]. In C. elegans whose dopaminergic neurons have been ablated or inhibited, there is marked failure to exhibit these high-angled turns when searching for food sources [61]. On the other hand, nematodes exposed to exogenous dopamine exhibit increases in high-angled turns, further supporting a role for dopamine in modulating food-related locomotion [80]. Dopamine also further contributes to $C$. elegans survival by causing a decrease in forward movement, in the presence of food, increasing the likelihood that the animals will stay near the newly discovered food source $[78,80]$. Learning in C. elegans is also modulated by dopamine [81]. The first time wild-type nematodes are exposed to "plate-tapping" they react by backing up; repeated plate-tapping results in decreased movement [82]. Olfactory adaptation, another type of learning, is responsive to dopamine [83]. Over prolonged exposure to an odorant, nematodes show decreases in their responses [84].

\section{Neurotransmitters: Serotonin}

Another biogenic amine neurotransmitter in C. elegans is serotonin. It is used by the following eight classes of neurons: 20 male-specific neurons (CP 0-9, R1, R3, R9); two pharyngeal neurosecretory motor neurons (NSM), four hermaphrodite specific motor neurons (HSN and VC4-5), two amphid neurons (ADF) and three ring interneurons (RIH and AIM) [61]. Exposure to exogenous serotonin inhibits motor neurons related to locomotion and defecation, while also stimulating egg laying and pharyngeal pumping $[85,86]$. When food-deprived C. elegans move near a food source, their locomotion slows down. This response is dependent on serotonin release [61]. Bas-1 and cat4 (serotonin biosynthetic enzymes) mutants exhibit defects in this slowing process and, when treated with exogenous serotonin, these defects are reversed. For example, a food-deprived nematode will come to a complete stop upon entering a bacterial lawn versus a well-feed nematode that will just slow [61]. Serotonin signaling helps ensure that food-deprived nematodes do not leave a food source, while dopamine signaling encourages nematodes to stay within that source $[61,76,80]$. Synthesis of serotonin occurs in neurosecretory motor neurons (NSMs) that have sensory endings located in the lumen of the pharynx. It is hypothesized that these might play a role in sensing food. NSMs also have access to neurons outside the pharynx and pseudocoelom, which facilitates communication with the rest of the animal [87-89]. Thus, serotonergic neurons are located in areas that allow for very efficient signaling that encourages nematodes to remain in food-rich areas [61]

\section{Neurotransmitters: $\Gamma$-aminobutyric acid and glutamate}

$\Gamma$-aminobutyric acid (GABA) is also an important neurotransmitter in C. elegans that functions primarily at neuromuscular junctions [90] Its main functions are to relax muscles during foraging and locomotion and modulate defecation. Out of the 302 neurons in hermaphrodite $C$. elegans, 26 of them are GABAergic [91]. Interestingly, GABA is both inhibitory and excitatory in these worms [92]. The 19 ventral cord neurons comprise the inhibitory GABA neurons and their job is to inhibit muscle contractions during locomotion $[91,93]$. The excitatory GABAergic neurons are responsible for modulation defecation [91]. Glutamate is also responsible for both excitatory and inhibitory responses in C. elegans [94-96]. The majority of excitatory responses are mediated by ionotropic glutamate receptors (iGluRs) [96,97], which play a role in reversal following nose touch $[98,99]$.

\section{Neurotransmitters: Acetylcholine}

The neurotransmitter acetylcholine (ACh) is excitatory in these worms $[100,101]$. It is found at neuromuscular junctions and causes contractions in the muscle wall [101]. ACh is also a modulatory neurotransmitter that plays a role in locomotion, egg laying, pharyngeal pumping, defecation cycling and male mating [90]. Locomotion is by far the most important behavior controlled by ACh, involving both crawling (surfaces) and swimming (liquid) [102,103].

\section{Summary}

Due to the relative simplicity of their nervous system, C. elegans provide an in vivo model for studying neuronal injury with respect to single neurons [3]. They have been used for studies examining mechanisms associated with metal and pesticide toxicity, as well as general neurodegeneration $[1,25,29,104,105]$. Since the C. elegans nervous system has characteristics similar vertebrates, results from these worms allow for reasonable translation to humans [96], particularly relating to pesticide neurotoxicity. 


\section{General Pesticide Neurotoxicity}

\section{Organophosphates}

Agricultural pesticide poisoning is a major public health problem in the developing world, resulting in the deaths of at least 250,000 370,000 people annually [106]. Although numerous pesticide classes are used throughout the world, some of the more common are organophosphates (OPs) and dithiocarbamates (DTCs). Taken together, OPs and DTCs are the most used pesticides for pest control [107]. OPs, which contain phosphorous derived from phosphoric acid, are generally the most toxic of all pesticides to vertebrates [108] and exposure is a serious global health problem. It is estimated that there are, on average, more than 3 million poisonings reported per year [109]. OPs are absorbed rapidly via all routes (respiratory, gastrointestinal, ocular and dermal) and exposure effects can be immediate and/or long term $[109,110]$. The most prominent effect of OP exposure is excessive accumulation of ACh in the synaptic cleft resulting from the irreversible inhibition of acetylcholinesterase (AChE), the enzyme responsible for ACh catabolism [107]. The standard treatment for $\mathrm{OP}$ poisoning is the administration of atropine, a competitive ACh antagonist that reverses the effects of excess ACh at the synapses, or the use of nucleophilic oxime, pralidoxime or obidoxime, to regenerate AChE $[111,112]$. Other proposed mechanisms of OP toxicity include production of or increasing oxidative stress [113]. Either increasing reactive oxygen species (ROS) or decreasing antioxidants result in oxidative stress $[109,114]$. ROS have been implicated in inflammation, aging, mutations, carcinogenesis, degenerative and many other diseases. OPs induce oxidative stress and deplete ATP in vivo, as well as alter antioxidants enzymes such as superoxide dismutase (SOD) [115]. In vitro, markers such an increased ROS (hydroxyl, superoxide, or lipid peroxyl) and reduced glutathione levels have been observed in cultured lymphocyte cells exposed to OPs, further supporting the hypothesis that oxidative stress plays a prominent role in OP mechanisms of action [108].

\section{Carbamate pesticides}

DTCs are widely-used pesticides with typically low acute and chronic toxicity in humans [116-119]. Similar to OPs, carbamates are esters of phosphoric acid, phosphothioic acid, or carbamic acid. There is considerable structural diversity, however, in the side chains and it is typically these moieties that determine the toxicokinetics and toxicodynamics of pesticide poisoning [109]. Carbamate poisoning is less severe than that of OP exposure [120-122] even though carbamates may also inhibit AChE $[115,123]$. The latter, however, cause reversible inhibition [114]. Thus, AChE inhibition by carbamates lasts only minutes or hours, whereas the effects of OPs may last for 3 to 4 months. Thus, acute intoxication by carbamates generally resolves within a few hours, unless their exposure is combined with that of OPs [123]. It is likely that carbamates may also be involved in oxidative stress [124]. For example, the carbamate carbofuran increases oxidative stress in rat brains by inducing lipid peroxidation and diminishing antioxidant defenses [125]. Because AChE inhibition is reversible in carbamate poisoning, therapeutic treatment is less effective than treatment for OP poisoning [123]. Oxime antidote therapy is usually not needed for these patients and atropine treatment is usually adequate [122].

\section{Organophosphate Pesticides in C. elegans}

\section{Movement, behavior and LC50s}

Although early research with $C$. elegans and pesticides focused on the actual toxicity of agrochemicals in the soil nematode, more recent work has shifted to include C. elegans as the model organism in toxicity testing. Since then, C. elegans has been valuable in generating data in neurotoxicity studies involving OPs [126,127]. Importantly, studies have shown that the toxicity rank and mechanism of action in C. elegans are comparable to those observed in more traditional mammalian models [128]. For example, Cole et al. [105] found that 15 OPs elicited behavioral EC50 rankings in C. elegans consistent with LD50 rankings observed in rats and mice. In addition, five of six OPs known to exhibit AChE activity in mammals (dichlorvos, fensulfothion, methidathion, methyl parathion, parathion) similarly reduced cholinesterase activity in C.elegans. Interestingly, glyphosate and ethephon did not exhibit significant AChE activity and these two compounds are not strong cholinesterase inhibitors in mammals. Lethality, movement and $\mathrm{AChE}$ activity have all been used as endpoints to examine OP neurotoxicity [128]. Exposure to each of ten specific OPs resulted in significant movement reduction, supplying additional evidence that the mechanism of toxicity (AChE inhibition) in C. elegans is comparable to that in mammals. Furthermore, the LC50s for the ten OPs showed a significant degree of correlation with the previous LD50s for rats [128]. This study also demonstrated that utilizing LC50s and movement as toxic endpoints do not present some of the challenges involved in using $\mathrm{AChE}$ activity as an endpoint Additionally, the former were more consistent than solely relying on measurements of AChE activity [128]

\section{Feeding, growth and Reproduction}

While numerous studies have focused on the effects of OPs on $C$. elegans movement, effects on feeding have also been examined $[129,130]$. In a study using the OP chlorpyrifos, feeding decreased steadily as the worms were exposed to successively higher concentrations. EC50 values, concentrations necessary to decrease C. elegans feeding by $50 \%$, ranged from 1.0-2.2 $\mu \mathrm{M}$ [129]. Worms exposed to comparable concentrations of chlorpyrifos also showed greater sensitivity to the pesticide when feeding and/or reproduction were used as endpoints [130,131]. Exposure also results in adverse effects on growth in a concentration dependent manner. Even though nematodes exposed to concentrations below $30 \mu \mathrm{M}$ developed to the adult stage, they exhibited a decrease in body size [132]. Nematodes exposed to concentrations greater than 30 $\mu \mathrm{M}$ did not develop into adults and, at the highest concentration of chlorpyrifos tested $(75 \mu \mathrm{M})$, growth was arrested at the L2 larval stage [132]. A link may also exist regarding reductions in nematode growth via the disruption of neural development, although exposure levels were not established [104,132]. Another OP, parathion, is capable of significantly reducing reproductive output in C. elegans [131]. In reproduction assays using numerous agrochemicals, including diquat and paraquat, parathion more potently inhibited reproduction [129131]. Here, the EC50s related to the reproductive output of C. elegans, determined by counting the number of offspring produced by worms exposed to the compounds from the L4 larval stage to adulthood. With EC50s ranging from $1.14-2.17 \mu \mathrm{M}$, parathion was more toxic than any other compound tested by at least two orders of magnitude $[129,131]$.

\section{Changes in gene and protein expression}

C. elegans has been used to examine changes in gene and protein expression induced by these OPs [32,104]. These agrochemicals are known to target genes and their protein products, specifically associated with neuronal and muscle tissue, as well as genes involved in apoptosis. Exposure of worms to fenamiphos and dichlorvos caused detectable changes in expression of 87 of genes. Decreased expression levels were observed for $h s p-6$ (heat shock 70 protein), map-2 (methionine 
aminopeptidase) and $d h p-2$ (dihydropyrimidinase), while expression of trx-1 (thioredoxin), gst-15 (glutathione s-transferase) and tmd-2 (tropomodulin) increased [32]. Along with fluctuating levels of gene expression, 34 proteins also exhibited changes in expression [32]. For example, increases in the expression of annexin and ubiquitin c-terminal hydrolase were observed.

OPs are also known to alter the expression of certain genes regulated by the mediator subunit MDT- 1 and the GATA transcription factor ELT-2, as well as genes located downstream of daf-16 [104]. Determination of this dysregulation has been facilitated by the fact that the C.elegans genome has been sequenced. Loss of function of these transcription factors can lead to abnormal induction of genes related to generalized toxic stress responses, innate immunity, detoxication and response to ingested material [104]. OP exposure can also lead to apoptotic events in both mammals and C. elegans [133-135] and numerous genes and proteins involved in apoptosis have been shown to have altered expression levels. For instance, an anti-apoptotic gene found in humans (map-2) was down-regulated and the abundance of a protein involved in the engulfment stage of apoptosis (NEX-1) increased [32]. Mutation in deg-3, which codes for a nicotinic AChR, leads to neurodegeneration similar to that observed in C. elegans after OP exposure. In human astrocytes, expression levels of numerous genes are dysregulated $[136,137]$ and these results have been duplicated in C. elegans [32,104]. Finally, medium and high-throughput screenings utilizing the complex object parametric analyzer and sorter (COPAS) flow sorting system have been used to assess the toxicity of OPs on C. elegans feeding, growth, reproduction and locomotion [130,131]. While this high-throughput technique is not unique to work with OPs, it further demonstrates the ability of using in vitro sorting techniques with a whole model organism to obtain vast quantities of data in relatively short periods of time.

\section{Carbamate Pesticides in C. elegans}

\section{Movement and reproduction}

C. elegans has also been used to examine the order and mechanism of toxicity of carbamates. In a study by Melstrom and Williams [138], toxicity rankings determined from movement-concentration curves displayed a high degree of correlation to oral acute $\mathrm{LD}_{50}$ rankings in rats and mice. Similar to observations in mammalian models, carbamate exposure also resulted in AChE inhibition, as indicated by a reduction in movement. For example, studies involving the carbamate insecticide aldicarb produced results consistent with compounds exhibiting AChE inhibition [139]. Aldicarb, an AChE inhibitor, considerably reduced tail thrashing and overall movement in the nematode. Additionally, reproduction was negatively affected, as worms treated with aldicarb displayed a decrease in brood size compared to control [139].

\section{Oxidative stress and reactive oxygen species}

The herbicide paraquat and the pesticide rotenone have been studied in C. elegans [3]. Paraquat, which is known to cause oxidative stress [140] in vertebrates through the production of ROS, also does so in C. elegans. Furthermore, mutant C. elegans strains lacking superoxide dismutase (SOD) enzymes SOD-1 and SOD-2 showed increased vulnerability to paraquat toxicity. In contrast, those containing greater levels of SOD, as well as increased expression of the $\omega$-class glutathione transferase ( $g s t-1)$ showed decreased susceptibility to the toxic effects of paraquat [3], implying a role of ROS or oxidative stress. The role of rotenone as a contributing factor to the etiology of Parkinson's disease has also been studied in C. elegans. Rotenone disrupts NADH- dehydrogenase in mitochondrial complex I. The role of complex I in preventing rotenone toxicity has been demonstrated in C. elegans, as strains with mutations in mitochondrial complex I showed increased vulnerability to the toxicity of rotenone [3]. Worms containing modified genes associated with Parkinson's disease were also more susceptible to oxidative damage due to rotenone exposure [141,142]. This illustrates the importance of these genes in the prevention of rotenone toxicity and oxidative stress in dopaminergic neurons.

\section{Manganese-containing dithiocarbamate fungicides}

Manganese-containing dithiocarbamate fungicides, such as maneb and mancozeb, have been researched heavily due to their neurotoxicity [143-145]. Manganese exposure by itself has been shown to result in a variety of detrimental effects in C. elegans [146-148]. One study demonstrates that even short exposures $(30 \mathrm{~min})$ to manganese result in production of ROS, as evidenced by a drastic increase in glutathione levels [143]. In this study, worms exposed to $50 \mathrm{mM}$ of $\mathrm{MnCl} 2$ experienced a two-fold increase in the amount of ROS production. Additionally, acute Mn exposure can lead to mitochondrial inhibition by disrupting mitochondrial membrane potential $(\Delta \psi)$ and oxygen consumption. Oxidative stress also resulted in the neurodegeneration of dopaminergic (DAergic) neurons, indicated by the fact that treated worms showed a significant decrease in DA concentration compared to untreated worms [143]. Similar neurodegeneration has been shown following exposure to mancozeb [144,145].

C. elegans studies have also confirmed that manganese exposure may have an additive effect on DAergic neurodegeneration in neurons containing $\alpha$-synuclein protein aggregates. Various labs have concluded that the C. elegans SMF-1 transporter, an analogue of the divalent metal transporter (DMT-1) found in humans, is important in the degeneration of these neurons [146,147,149,150]. Results in C. elegans indicate that this transporter plays a significant role in neurotoxicity by transporting manganese into the cell where it can induce numerous intracellular changes.

\section{Discussion and Conclusions}

C. elegans has continued to gain in popularity in toxicological research as a model organism over the last three decades. This is partially because these worms are only a millimeter in length and are relatively inexpensive to maintain. Furthermore, data generated in C. elegans has successfully complemented and supplemented data obtained from traditional mammalian model organisms. The ability to easily manipulate its genome via interfering RNA (iRNA), allows for exploration of both gene and protein function without the difficulties associated with more traditional knock-out and knockdown techniques. Other techniques previously available for in vitro models, i.e. flow sorting, green-fluorescent tags, histochemical analysis, can now be used with ease in the transparent $C$. elegans. In this review, we examined how this nematode has been used to examine the toxic effects of organophosphate and dithiocarbamate pesticides. End points include gene expression, $\mathrm{LC}_{50} \mathrm{~s}$, various $\mathrm{EC}_{50} \mathrm{~s}$, movement, feeding and/ or brood size have been studied, emphasizing the variety of rich data that can be obtained using this simple organism. While more labs are beginning to incorporate $C$. elegans into their research, it is likely that the toxicology community is only just beginning to utilize the power of this important organism.

\section{References}

1. Silverman GA, Luke CJ, Bhatia SR, Long OS, Vetica AC, et al. (2009) Modeling Molecular and Cellular Aspects of Human Disease Using the Nematode Caenorhabditis elegans. Pediatr Res 65: 10-18. 
Citation: McVey KA, Mink JA, Snapp IB, Timberlake WS, Todt CE, et al. (2012) Caenorhabditis elegans: An Emerging Model System for Pesticide Neurotoxicity. J Environment Analytic Toxicol S4:003. doi:10.4172/2161-0525.S4-003

2. Brenner S (1974) The Genetics of Caenorhabditis elegans. Genetics 77: 71-94

3. Leung MC, Williams PL, Benedetto A, Au C, Helmcke KJ, et al. (2008) Caenorhabditis elegans: An Emerging Model in Biomedical and Environmental Toxicology. Toxicol Sci 106: 5-28.

4. Teschendorf D, Link CD (2009) What Have Worm Models Told Us About the Mechanisms of Neuronal Dysfunction in Human Neurodegenerative Diseases? Mol Neurodegener 4: 38.

5. Blaxter M (2011) Nematodes: The Worm and Its Relatives. PLoS Biol 9: e1001050.

6. Varshney LR, Chen BL, Paniagua E, Hall DH, Chklovskii DB (2011) Structura Properties of the Caenorhabditis elegans Neuronal Network. PLoS Comput Biol 7: e1001066.

7. Zhang X, Zhang Y (2009) Neural-Immune Communication in Caenorhabditis elegans. Cell Host Microbe 5: 425-429.

8. Mills H, Wragg R, Hapiak V, Castelletto M, Zahratka J, et al. (2011) Monoamines and Neuropeptides Interact to Inhibit Aversive Behaviour in Caenorhabditis elegans. EMBO J 31: 667-678.

9. Milward K, Busch KE, Murphy RJ, de Bono M, Olofsson B (2011) Neuronal and Molecular Substrates for Optimal Foraging in Caenorhabditis elegans. Proc Natl Acad Sci USA 108: 20672-20677.

10. Yemini E, Kerr RA, Schafer WR (2011) Tracking Movement Behavior of Multiple Worms on Food. Cold Spring Harb Protoc 2011: 1483-1487.

11. Hart AC, Chao MY (2010) From Odors to Behaviors in Caenorhabditis elegans.

12. Felix MA, Braendle C (2010) The Natural History of Caenorhabditis elegans Curr Biol 20: R965-R969.

13. Grishok A, Tabara H, Mello CC (2000) Genetic Requirements for Inheritance of RNAi in C. elegans. Science 287: 2494-2497.

14. Sharp PA (1999) RNAi and Double-Strand RNA. Genes Dev 13: 139-141.

15. Tabara H, Grishok A, Mello CC (1998) RNAi in C. elegans: Soaking in the Genome Sequence. Science 282: 430-431.

16. Burton NO, Burkhart KB, Kennedy S (2011) Nuclear RNAi Maintains Heritable Gene Silencing in Caenorhabditis elegans. Proc Natl Acad Sci USA 108: 19683-19688.

17. Cipriani PG, Piano F (2011) RNAi Methods and Screening: RNAi Based HighThroughput Genetic Interaction Screening. Methods Cell Biol 106: 89-111.

18. Zhuang JJ, Hunter CP (2011) RNA Interference in Caenorhabditis elegans: Uptake, Mechanism, and Regulation. Parasitology 1-14.

19. Von Stetina SE, Watson JD, Fox RM, Olszewski KL, Spencer WC, et al. (2007) Cell-Specific Microarray Profiling Experiments Reveal a Comprehensive Picture of Gene Expression in the C. elegans Nervous System. Genome Biol 8: R135.

20. Calahorro F, Ruiz-Rubio M (2011) Caenorhabditis elegans as an Experimenta Tool for the Study of Complex Neurological Diseases: Parkinson's Disease, Alzheimer's Disease and Autism Spectrum Disorder. Invert Neurosci 11: 73-83.

21. Dehay B, Bezard E (2011) New Animal Models of Parkinson's Disease. Mov Disord 26: 1198-1205.

22. Harrington AJ, Knight AL, Caldwell GA, Caldwell KA (2011) Caenorhabditis elegans as a Model System for Identifying Effectors of Alpha-Synuclein Misfolding and Dopaminergic Cell Death Associated with Parkinson's Disease. Methods 53: 220-225.

23. Luo Y, Wu Y, Brown M, Link CD (2009) Caenorhabditis elegans Model for Initia Screening and Mechanistic Evaluation of Potential New Drugs for Aging and Alzheimer's Disease.

24. Zheng M, Gorelenkova O, Yang J, Feng Z (2011) A Liquid Phase Based C. elegans Behavioral Analysis System Identifies Motor Activity Loss in a Nematode Parkinson's Disease Model. J Neurosci Methods 204: 234-237.

25. Wolozin B, Gabel C, Ferree A, Guillily M, Ebata A (2011) Watching Worms Whither: Modeling Neurodegeneration in C. elegans. Prog Mol Biol Transl Sci 100: 499-514.

26. Corsi AK (2006) A Biochemist's Guide to Caenorhabditis elegans. Ana Biochem 359: 1-17.
27. Joshi PM, Riddle MR, Djabrayan NJ, Rothman JH (2011) Caenorhabditis elegans as a Model for Stem Cell Biology. Dev Dyn 239: 1539-1554

28. Morgan DE, Crittenden SL, Kimble J (2011) The C. elegans Adult Male Germline: Stem Cells and Sexual Dimorphism. Dev Biol 346: 204-214.

29. Avila D, Helmcke K, Aschner M (2011) The Caenorhabiditis elegans Model as a Reliable Tool in Neurotoxicology. Hum Exp Toxicol.

30. Combes D, Fedon Y, Toutant JP, Arpagaus M (2001) Acetylcholinesterase Genes in the Nematode Caenorhabditis elegans. Int Rev Cytol 209: 207-239.

31. Peterson RT, Nass R, Boyd WA, Freedman JH, Dong K, et al. (2008) Use of Non-Mammalian Alternative Models for Neurotoxicological Study. Neurotoxicology 29: 546-555

32. Lewis JA, Szilagyi M, Gehman E, Dennis WE, Jackson DA (2009) Distinct Patterns of Gene and Protein Expression Elicited by Organophosphorus Pesticides in Caenorhabditis elegans. BMC Genomics 10: 202.

33. Ballatori N, Villalobos AR (2002) Defining the Molecular and Cellular Basis of Toxicity Using Comparative Models. Toxicol Appl Pharmacol 183: 207-220.

34. de Bono M, Maricq AV (2005) Neuronal Substrates of Complex Behaviors in C. elegans. Annu Rev Neurosci 28: 451-501.

35. Oikonomou G, Shaham S (2011) The Glia of Caenorhabditis elegans. Glia 59 1253-1263.

36. Majewska A, Yuste R (2001) Topology of Gap Junction Networks in C. elegans J Theor Biol 212: 155-167.

37. Lu J, Tapia JC, White OL, Lichtman JW (2009) The Interscutularis Muscle Connectome. PLoS Biol 7: e32.

38. Jin Y (2005) Synaptogenesis, in Wormbook, Jorgensen E, Kaplan J, Editors, The C. elegans Research Community.

39. Lockery SR (2011) The Computational Worm: Spatial Orientation and Its Neuronal Basis in C. elegans. Curr Opin Neurobiol 21: 782-790.

40. Piggott BJ, Liu J, Feng Z, Wescott SA, Xu XZ (2011) The Neural Circuits and Synaptic Mechanisms Underlying Motor Initiation in C. elegans. Cell 147: 922 933.

41. Sugi T, Nishida Y, Mori I (2011) Regulation of Behavioral Plasticity by Systemic Temperature Signaling in Caenorhabditis elegans. Nat Neurosci 14: 984-992.

42. Bargmann Cl, Kaplan JM (1998) Signal Transduction in the Caenorhabditis elegans Nervous System. Annu Rev Neurosci 21: 279-308.

43. Satterlee JS, Sasakura H, Kuhara A, Berkeley M, Mori I, et al. (2001) Specification of Thermosensory Neuron Fate in C. elegans Requires Ttx-1, a Homolog of Otd/Otx. Neuron 31: 943-956.

44. Anderson JL, Albergotti L, Ellebracht B, Huey RB, Phillips PC (2011) Does Thermoregulatory Behavior Maximize Reproductive Fitness of Natural Isolates of Caenorhabditis elegans? BMC Evol Biol 11: 157.

45. Anderson JL, Albergotti L, Proulx S, Peden C, Huey RB, et al. (2007) Therma Preference of Caenorhabditis elegans: A Null Model and Empirical Tests. J Exp Biol 210: 3107-3116

46. Devaney E (2006) Thermoregulation in the Life Cycle of Nematodes. Int Parasitol 36: 641-649.

47. Ramot D, Maclnnis BL, Lee HC, Goodman MB (2008) Thermotaxis Is a Robust Mechanism for Thermoregulation in Caenorhabditis elegans Nematodes. $J$ Neurosci 28:12546-12557.

48. Bae YK, Barr MM (2008) Sensory Roles of Neuronal Cilia: Cilia Development, Morphogenesis, and Function in C. elegans. Front Biosci 13: 5959-5974.

49. Maricq AV, Peckol E, Driscoll M, Bargmann Cl (1995) Mechanosensory Signalling in C. elegans Mediated by the GIr-1 Glutamate Receptor. Nature 378: 78-81.

50. Chao MY, Hart AC (2003) Sensory Biology: How the Nose Knows. Curr Bio 13: R226-R228.

51. Kindt KS, Viswanath V, Macpherson L, Quast K, Hu H, et al. (2007) Caenorhabditis elegans Trpa-1 Functions in Mechanosensation. Nat Neurosci 10: $568-577$

52. Kaplan JM, Horvitz HR (1993) A Dual Mechanosensory and Chemosensory Neuron in Caenorhabditis elegans. Proc Natl Acad Sci USA 90: 2227-2231. 
Citation: McVey KA, Mink JA, Snapp IB, Timberlake WS, Todt CE, et al. (2012) Caenorhabditis elegans: An Emerging Model System for Pesticide Neurotoxicity. J Environment Analytic Toxicol S4:003. doi:10.4172/2161-0525.S4-003

53. Albeg A, Smith CJ, Chatzigeorgiou M, Feitelson DG, Hall DH, et al. (2011) C. elegans Multi-Dendritic Sensory Neurons: Morphology and Function. Mol Cell Neurosci 46: 308-317.

54. Murray RL, Kozlowska JL, Cutter AD (2011) Heritable Determinants of Male Fertilization Success in the Nematode Caenorhabditis elegans. BMC Evol Biol 11: 99

55. Whittaker AJ, Sternberg PW (2009) Coordination of Opposing Sex-Specific and Core Muscle Groups Regulates Male Tail Posture During Caenorhabditis elegans Male Mating Behavior. BMC Biol 7: 33

56. Koo PK, Bian X, Sherlekar AL, Bunkers MR, Lints R (2011) The Robustness of Caenorhabditis elegans Male Mating Behavior Depends on the Distributed Properties of Ray Sensory Neurons and Their Output through Core and MaleSpecific Targets. J Neurosci 31: 7497-7510.

57. Li H, Avery L, Denk W, Hess GP (1997) Identification of Chemical Synapses in the Pharynx of Caenorhabditis elegans. Proc Natl Acad Sci USA 94: 59125916.

58. Sakata K, Shingai R (2004) Neural Network Model to Generate Head Swing in Locomotion of Caenorhabditis elegans. Network 15: 199-216.

59. Sieburth D, Ch'ng Q, Dybbs M, Tavazoie M, Kennedy S, et al. (2005) Systematic Analysis of Genes Required for Synapse Structure and Function. Nature 436: 510-517.

60. Yan D, Noma K, Jin Y (2011) Expanding Views of Presynaptic Terminals: New Findings from Caenorhabditis elegans. Curr Opin Neurobiol.

61. Chase DL, Koelle MR (2007) Biogenic Amine Neurotransmitters in C. elegans. WormBook 1-15

62. Bendesky A, Tsunozaki M, Rockman MV, Kruglyak L, Bargmann Cl (2011) Catecholamine Receptor Polymorphisms Affect Decision-Making in C. elegans. Nature 472: 313-318.

63. Hardaker LA, Singer E, Kerr R, Zhou G, Schafer WR (2001) Serotonin Modulates Locomotory Behavior and Coordinates Egg-Laying and Movement in Caenorhabditis elegans. J Neurobiol 49: 303-313.

64. Harris G, Mills H, Wragg R, Hapiak V, Castelletto M, et al. (2011) The Monoaminergic Modulation of Sensory-Mediated Aversive Responses in Caenorhabditis elegans Requires Glutamatergic/Peptidergic Cotransmission. J Neurosci 30: 7889-7899.

65. Horvitz HR, Chalfie M, Trent C, Sulston JE, Evans PD (1982) Serotonin and Octopamine in the Nematode Caenorhabditis elegans. Science 216: 1012 1014.

66. Rex E, Molitor SC, Hapiak V, Xiao H, Henderson M, et al. (2004) Tyramine Receptor (Ser-2) Isoforms Are Involved in the Regulation of Pharyngeal Pumping and Foraging Behavior in Caenorhabditis elegans. J Neurochem 91 1104-1115.

67. Wragg RT, Hapiak V, Miller SB, Harris GP, Gray J, et al. (2007) Tyramine and Octopamine Independently Inhibit Serotonin-Stimulated Aversive Behaviors in Caenorhabditis elegans through Two Novel Amine Receptors. J Neurosci 27: 13402-13412.

68. Packham R, Walker RJ, Holden-Dye L (2011) The Effect of a Selective Octopamine Antagonist, Epinastine, on Pharyngeal Pumping in Caenorhabditis elegans. Invert Neurosci 10: 47-52.

69. Branicky R, Schafer WR (2009) Tyramine: A New Receptor and a New Role a the Synapse. Neuron 62: 458-460.

70. Alkema MJ, Hunter-Ensor M, Ringstad N, Horvitz HR (2005) Tyramine Functions Independently of Octopamine in the Caenorhabditis elegans Nervous System. Neuron 46: 247-260

71. Rex E, Komuniecki RW (2002) Characterization of a Tyramine Receptor from Caenorhabditis elegans. J Neurochem 82: 1352-1359.

72. Rex E, Hapiak V, Hobson R, Smith K, Xiao H, et al. (2005) Tyra-2 (F01e11.5): A Caenorhabditis elegans Tyramine Receptor Expressed in the Mc and Nsm Pharyngeal Neurons. J Neurochem 94: 181-191

73. McDonald PW, Jessen T, Field JR, Blakely RD (2006) Dopamine Signaling Architecture in Caenorhabditis elegans. Cell Mol Neurobiol 26: 593-618.

74. Kindt KS, Quast KB, Giles AC, De S, Hendrey D, et al. (2007) Dopamine Mediates Context-Dependent Modulation of Sensory Plasticity in C. elegans. Neuron 55: 662-676.
75. Qin J, Wheeler AR (2007) Maze Exploration and Learning in C. elegans. Lab Chip 7: 186-192.

76. Luedtke S, O'Connor V, Holden-Dye L, Walker RJ (2011) The Regulation of Feeding and Metabolism in Response to Food Deprivation in Caenorhabditis elegans. Invert Neurosci 10: 63-76.

77. Suo S, Culotti JG, Van Tol HH (2009) Dopamine Suppresses Octopamine Signaling in C. elegans: Possible Involvement of Dopamine in the Regulation of Lifespan. Aging (Albany NY) 1: 870-874.

78. Hills T, Brockie PJ, Maricq AV (2004) Dopamine and Glutamate Control AreaRestricted Search Behavior in Caenorhabditis elegans. J Neurosci 24: $1217-$ 1225.

79. Komuniecki RW, Hobson RJ, Rex EB, Hapiak VM, Komuniecki PR (2004) Biogenic Amine Receptors in Parasitic Nematodes: What Can Be Learned from Caenorhabditis elegans? Mol Biochem Parasitol 137: 1-11.

80. Sawin ER, Ranganathan R, Horvitz HR (2000) C. elegans Locomotory Rate Is Modulated by the Environment through a Dopaminergic Pathway and by Experience through a Serotonergic Pathway. Neuron 26: 619-631.

81. Stephens GJ, Johnson-Kerner B, Bialek W, Ryu WS (2011) From Modes to Movement in the Behavior of Caenorhabditis elegans. PLoS One 5: e13914.

82. Giles AC, Rankin CH (2009) Behavioral and Genetic Characterization of Habituation Using Caenorhabditis elegans. Neurobiol Learn Mem 92: 139-146.

83. L'Etoile ND, Bargmann Cl (2000) Olfaction and Odor Discrimination Are Mediated by the C. elegans Guanylyl Cyclase Odr-1. Neuron 25: 575-586.

84. L'Etoile ND, Coburn CM, Eastham J, Kistler A, Gallegos G, et al. (2002) The Cyclic GMP-Dependent Protein Kinase Egl-4 Regulates Olfactory Adaptation in C. elegans. Neuron 36: 1079-1089.

85. Jafari G, Xie Y, Kullyev A, Liang B, Sze JY (2011) Regulation of Extrasynaptic 5-HT by Serotonin Reuptake Transporter Function in 5-Ht-Absorbing Neurons Underscores Adaptation Behavior in Caenorhabditis elegans. J Neurosci 31 8948-8957.

86. Zhang M, Chung SH, Fang-Yen C, Craig C, Kerr RA, et al. (2008) A SelfRegulating Feed-Forward Circuit Controlling C. elegans Egg-Laying Behavior. Curr Biol 18: 1445-1455

87. Axang C, Rauthan M, Hall DH, Pilon M (2008) Developmental Genetics of the C. elegans Pharyngeal Neurons NSML and NSMR. BMC Dev Biol 8: 38.

88. Hobson RJ, Hapiak VM, Xiao H, Buehrer KL, Komuniecki PR, et al. (2006) Ser7, a Caenorhabditis elegans 5-HT7-Like Receptor, Is Essential for the 5-HT Stimulation of Pharyngeal Pumping and Egg Laying. Genetics 172: 159-169.

89. Niacaris T, Avery L (2003) Serotonin Regulates Repolarization of the C. elegans Pharyngeal Muscle. J Exp Biol 206: 223-231.

90. Richmond JE, Jorgensen EM (1999) One Gaba and Two Acetylcholine Receptors Function at the C. Elegans Neuromuscular Junction. Nat Neurosci, 2: 791-797.

91. Jorgensen EM (2005) GABA. WormBook 1-13.

92. Schuske K, Beg AA, Jorgensen EM (2004) The GABA Nervous System in C. elegans. Trends Neurosci 27: 407-414.

93. McIntire SL, Jorgensen E, Kaplan J, Horvitz HR (1993) The GABAergic Nervous System of Caenorhabditis elegans. Nature 364: 337-341.

94. Brockie PJ, Madsen DM, Zheng Y, Mellem J, Maricq AV (2001) Differentia Expression of Glutamate Receptor Subunits in the Nervous System of Caenorhabditis elegans and Their Regulation by the Homeodomain Protein Unc-42. J Neurosci 21: 1510-1522.

95. Brockie PJ, Maricq AV (2003) Ionotropic Glutamate Receptors in Caenorhabditis elegans. Neurosignals 12: 108-125.

96. Brockie PJ, Maricq AV (2006) Ionotropic Glutamate Receptors: Genetics, Behavior and Electrophysiology. WormBook 1-16.

97. Zheng Y, Brockie PJ, Mellem JE, Madsen DM, Maricq AV (1999) Neurona Control of Locomotion in C. elegans Is Modified by a Dominant Mutation in the GIr-1 Ionotropic Glutamate Receptor. Neuron 24: 347-361.

98. Brockie PJ, Mellem JE, Hills T, Madsen DM, Maricq AV (2001) The C. elegans Glutamate Receptor Subunit Nmr-1 Is Required for Slow NMDA-Activated Currents That Regulate Reversal Frequency During Locomotion. Neuron 31: 617-630. 
Citation: McVey KA, Mink JA, Snapp IB, Timberlake WS, Todt CE, et al. (2012) Caenorhabditis elegans: An Emerging Model System for Pesticide Neurotoxicity. J Environment Analytic Toxicol S4:003. doi:10.4172/2161-0525.S4-003

99. Mellem JE, Brockie PJ, Zheng Y, Madsen DM, Maricq AV (2002) Decoding of Polymodal Sensory Stimuli by Postsynaptic Glutamate Receptors in C elegans. Neuron 36: 933-944.

100. Duerr JS, Han HP, Fields SD, Rand JB (2008) Identification of Major Classes of Cholinergic Neurons in the Nematode Caenorhabditis Elegans. J Comp Neurol 506: 398-408.

101. Rand JB (2007) Acetylcholine. WormBook 1-21.

102. Ghosh R, Emmons SW (2010) Calcineurin and Protein Kinase G Regulate C. elegans Behavioral Quiescence During Locomotion in Liquid. BMC Genet 11: 7

103. Mullen GP, Mathews EA, Vu MH, Hunter JW, Frisby DL, et al. (2007) Choline Transport and De Novo Choline Synthesis Support Acetylcholine Biosynthesis in Caenorhabditis elegans Cholinergic Neurons. Genetics 177: 195-204.

104. Vinuela A, Snoek LB, Riksen JA, Kammenga JE (2011) Genome-Wide Gene Expression Analysis in Response to Organophosphorus Pesticide Chlorpyrifos and Diazinon in C. elegans. PLoS One 5: e12145.

105. Cole RD, Anderson GL, Williams PL (2004) The Nematode Caenorhabditis Elegans as a Model of Organophosphate-Induced Mammalian Neurotoxicity. Toxicol Appl Pharmacol 194: 248-256.

106. Dawson AH, Eddleston M, Senarathna L, Mohamed F, Gawarammana I, et al (2010) Acute Human Lethal Toxicity of Agricultural Pesticides: A Prospective Cohort Study. PLoS Med 7: e1000357.

107. Vidyasagar J (2004) Oxidative Stress and Antioxidant Status in Acute Organophosphorous Insecticide Poisoning. Indian J Pharm 36.

108.Soltaninejad K, Abdollahi M (2009) Current Opinion on the Science of Organophosphate Pesticides and Toxic Stress: A Systematic Review. Med Sci Monit 15: RA75-RA90.

109. Kwong TC (2002) Organophosphate Pesticides: Biochemistry and Clinical Toxicology. Ther Drug Monit 24: 144-149.

110. Vaccari A, Saba P, Mocci I, Ruiu S (1999) Dithiocarbamate Pesticides Affect Glutamate Transport in Brain Synaptic Vesicles. J Pharmacol Exp Ther 288 $1-5$

111. Bajgar J, Fusek J, Kuca K, Bartosova L, Jun D (2007) Treatment of Organophosphate Intoxication Using Cholinesterase Reactivators: Facts and Fiction. Mini Rev Med Chem 7: 461-466.

112. Wagner SL (1997) Diagnosis and Treatment of Organophosphate and Carbamate Intoxication. Occup Med 12: 239-249.

113. El-Demerdash FM (2011) Lipid Peroxidation, Oxidative Stress and Acetylcholinesterase in Rat Brain Exposed to Organophosphate and Pyrethroid Insecticides. Food Chem Toxicol 49: 1346-1352.

114. Leibson T, Lifshitz M (2008) Organophosphate and Carbamate Poisoning: Review of the Current Literature and Summary of Clinical and Laboratory Experience in Southern Israel. Isr Med Assoc J 10: 767-770.

115. Milatovic D, Gupta RC, Aschner M (2006) Anticholinesterase Toxicity and Oxidative Stress. Scientific World Journal 6: 295-310.

116. Caldas ED, De Souza MV, Jardim AN (2011) Dietary Risk Assessment of Organophosphorus and Dithiocarbamate Pesticides in a Total Diet Study at a Brazilian University Restaurant. Food Addit Contam Part A Chem Anal Control Expo Risk Assess 28: 71-79.

117. Irons RD, Stillman WS, Pyatt DW, Yang Y, Le A, et al. (2001) Comparative Toxicity of Dithiocarbamates and Butadiene Metabolites in Human Lymphoid and Bone Marrow Cells. Chem Biol Interact 135-136: 615-25.

118. Sekiyama M, Tanaka M, Gunawan B, Abdoellah O, Watanabe C (2007) Pesticide Usage and Its Association with Health Symptoms among Farmers in Rural Villages in West Java, Indonesia. Environ Sci 14: 23-33.

119. Viquez OM, Lai B, Ahn JH, Does MD, Valentine HL, et al. (2009) N,NDiethyldithiocarbamate Promotes Oxidative Stress Prior to Myelin Structural Changes and Increases Myelin Copper Content. Toxicol Appl Pharmacol 239 71-79.

120.El-Naggar Ael R, Abdalla MS, El-Sebaey AS, Badawy SM (2009) Clinical Findings and Cholinesterase Levels in Children of Organophosphates and Carbamates Poisoning. Eur J Pediatr 168: 951-956.

121.Lee BK, Jeung KW, Lee HY, Jung YH (2011) Mortality Rate and Pattern
Following Carbamate Methomyl Poisoning. Comparison with Organophosphate Poisoning of Comparable Toxicity. Clin Toxicol (Phila) 49: 828-833.

122. Rosman Y, Makarovsky I, Bentur Y, Shrot S, Dushnistky T, et al. (2009) Carbamate Poisoning: Treatment Recommendations in the Setting of a Mass Casualties Event. Am J Emerg Med 27: 1117-1124.

123. Bjorling-Poulsen M, Andersen HR, Grandjean P (2008) Potential Developmental Neurotoxicity of Pesticides Used in Europe. Environ Health 7: 50 .

124. Banerjee BD, Seth V, Bhattacharya A, Pasha ST, Chakraborty AK (1999) Biochemical Effects of Some Pesticides on Lipid Peroxidation and FreeRadical Scavengers. Toxicol Lett 107: 33-47.

125. Kamboj SS, Kumar V, Kamboj A, Sandhir R (2008) Mitochondrial Oxidative Stress and Dysfunction in Rat Brain Induced by Carbofuran Exposure. Cell Mol Neurobiol 28: 961-969.

126. Roh JY, Choi J (2008) Ecotoxicological Evaluation of Chlorpyrifos Exposure on the Nematode Caenorhabditis elegans. Ecotoxicol Environ Saf 71: 483489.

127. Ruan QL, Ju JJ, Li YH, Liu R, Pu YP, et al. (2009) Evaluation of Pesticide Toxicities with Differing Mechanisms Using Caenorhabditis elegans. J Toxicol Environ Health A 72: 746-751.

128. Rajini PS, Melstrom P, Williams PL (2008) A Comparative Study on the Relationship between Various Toxicological Endpoints in Caenorhabditis elegans Exposed to Organophosphorus Insecticides. J Toxicol Environ Health A 71: 1043-1050.

129. Boyd WA, McBride SJ, Freedman JH (2007) Effects of Genetic Mutations and Chemical Exposures on Caenorhabditis elegans Feeding: Evaluation of a Novel, High-Throughput Screening Assay. PLoS One 2: e1259.

130. Boyd WA, Smith MV, Kissling GE, Freedman JH (2011) Medium- and HighThroughput Screening of Neurotoxicants Using C. elegans. Neurotoxico Teratol 32: 68-73

131. Boyd WA, McBride SJ, Rice JR, Snyder DW, Freedman JH (2011) A HighThroughput Method for Assessing Chemical Toxicity Using a Caenorhabditis Elegans Reproduction Assay. Toxicol Appl Pharmacol 245: 153-159.

132. Boyd WA, Smith MV, Kissling GE, Rice JR, Snyder DW, et al. (2009) Application of a Mathematical Model to Describe the Effects of Chlorpyrifos on Caenorhabditis Elegans Development. PLoS One 4: e7024.

133. Aluigi MG, Guida C, Falugi C (2011) Apoptosis as a Specific Biomarker of Diazinon Toxicity in NTERA2-D1 Cells. Chem Biol Interact 187: 299-303.

134. Carlson K, Jortner BS, Ehrich M (2000) Organophosphorus CompoundInduced Apoptosis in Sh-Sy5y Human Neuroblastoma Cells. Toxicol App Pharmacol 168: 102-113.

135. Li Q, Kobayashi M, Kawada T (2009) Chlorpyrifos Induces Apoptosis in Human T Cells. Toxicology 255: 53-57.

136. Betancourt AM, Burgess SC, Carr RL (2006) Effect of Developmental Exposure to Chlorpyrifos on the Expression of Neurotrophin Growth Factors and Cell-Specific Markers in Neonatal Rat Brain. Toxicol Sci 92: 500-506.

137. Mense SM, Sengupta A, Lan C, Zhou M, Bentsman G, et al. (2006) The Common Insecticides Cyfluthrin and Chlorpyrifos Alter the Expression of a Subset of Genes with Diverse Functions in Primary Human Astrocytes. Toxico Sci 93: 125-135.

138. Melstrom PC, Williams PL (2007) Reversible Ache Inhibitors in C. elegans Vs. Rats, Mice. Biochem Biophys Res Commun 357: 200-205.

139. Wren JF, Kille P, Spurgeon DJ, Swain S, Sturzenbaum SR, et al. (2011) Application of Physiologically Based Modelling and Transcriptomics to Probe the Systems Toxicology of Aldicarb for Caenorhabditis elegans (Maupas 1900). Ecotoxicology 20: 397-408

140. Tanner CM, Kamel F, Ross GW, Hoppin JA, Goldman SM, et al. (2011) Rotenone, Paraquat, and Parkinson's Disease. Environ Health Perspect 119: 866-872.

141. Saha S, Guillily MD, Ferree A, Lanceta J, Chan D, et al. (2009) LRRK2 Modulates Vulnerability to Mitochondrial Dysfunction in Caenorhabditis elegans. J Neurosci 29: 9210-9218.

142. Wolozin B, Saha S, Guillily M, Ferree A, Riley M (2008) Investigating Convergent Actions of Genes Linked to Familial Parkinson's Disease. Neurodegener Dis 5: 182-185. 
Citation: McVey KA, Mink JA, Snapp IB, Timberlake WS, Todt CE, et al. (2012) Caenorhabditis elegans: An Emerging Model System for Pesticide Neurotoxicity. J Environment Analytic Toxicol S4:003. doi:10.4172/2161-0525.S4-003

143. Settivari R, Levora J, Nass R (2009) The Divalent Metal Transporter Homologues Smf-1/2 Mediate Dopamine Neuron Sensitivity in Caenorhabditis elegans Models of Manganism and Parkinson Disease. J Biol Chem 284 35758-35768.

144. Negga R, Rudd DA, Davis NS, Justice AN, Hatfield HE, et al. (2011) Exposure to $\mathrm{Mn} / \mathrm{Zn}$ Ethylene-Bis-Dithiocarbamate and Glyphosate Pesticides Leads to Neurodegeneration in Caenorhabditis elegans. Neurotoxicology 32: 331-341.

145. Negga R, Stuart JA, Machen ML, Salva J, Lizek AJ, et al. (2011) Exposure to Glyphosate- and/or Mn/Zn-Ethylene-Bis-Dithiocarbamate-Containing Pesticides Leads to Degeneration of Gamma-Aminobutyric Acid and Dopamine Neurons in Caenorhabditis elegans. Neurotox Res.

146. Au C, Benedetto A, Anderson J, Labrousse A, Erikson K, et al. (2009) Smf-1, Smf-2 and Smf-3 DMT1 Orthologues Regulate and Are Regulated Differentially by Manganese Levels in C. elegans. PLoS One 4: e7792.
147. Au C, Benedetto A, Aschner M (2008) Manganese Transport in Eukaryotes: The Role of DMT1. Neurotoxicology 29: 569-576.

148. Benedetto A, Au C, Avila DS, Milatovic D, Aschner M (2011) Extracellula Dopamine Potentiates Mn-Induced Oxidative Stress, Lifespan Reduction, and Dopaminergic Neurodegeneration in a Bli-3-Dependent Manner in Caenorhabditis elegans. PLoS Genet 6 - e1001084

149. Martinez-Finley EJ, Aschner M (2011) Revelations from the Nematode Caenorhabditis elegans on the Complex Interplay of Metal Toxicological Mechanisms. J Toxicol 2011: 895236.

150. Martinez-Finley EJ, Avila DS, Chakraborty S, Aschner M (2011) Insights from Caenorhabditis Elegans on the Role of Metals in Neurodegenerative Diseases. Metallomics 3: 271-279.

151. Altun Z, Herndon L, Crocker C, Lints R, Hall D (2002-2010) Worm atlas.
This article was originally published in a special issue, Toxicology of Pesticides handled by Editor(s). Dr. Francisco Sanchez Bayo, Australia; Dr. Richard ORTEGA, France 